\title{
Luminescent hydroxylapatite nanoparticles by surface functionalization
}

\author{
Wei Wang and Donglu Shi ${ }^{\mathrm{a}}$ \\ Department of Chemical and Materials Engineering, University of Cincinnati, Cincinnati, Ohio 45221 \\ Jie Lian \\ Department of Geological Sciences, University of Michigan, Ann Arbor, Michigan 48109 \\ Yan Guo \\ Department of Chemical and Materials Engineering, University of Cincinnati, Cincinnati, Ohio 45221 \\ Guokui Liu \\ Chemistry Division, Argonne National Laboratory, Argonne, Illinois 60439 \\ Lumin Wang and Rodney C. Ewing \\ Department of Geological Sciences, University of Michigan, Ann Arbor, Michigan 48109; \\ Nuclear Engineering and Radiological Sciences, University of Michigan, Ann Arbor, Michigan 48109; \\ and Materials Science and Engineering, University of Michigan, Ann Arbor, Michigan 48109
}

(Received 10 August 2006; accepted 15 September 2006; published online 1 November 2006)

\begin{abstract}
Hydroxylapatite (HA) nanoparticles were functionalized by depositing rare-earth-doped $\mathrm{Y}_{2} \mathrm{O}_{3}$ nanoparticles on the surface, and the structural evolutions of both $\mathrm{HA}$ and $\mathrm{Y}_{2} \mathrm{O}_{3}$ phases at different annealing temperatures were investigated by $\mathrm{x}$-ray diffraction and transmission electron microscopy. Laser spectroscopy indicated that the surface functionalized HA nanoparticles exhibited strong visible emissions. No visible emissions were observed from rare-earth-doped $\mathrm{Y}_{2} \mathrm{O}_{3}$ without any substrate, suggesting a doping-induced environmental change of optically active rare-earth elements in the functionalized HA nanoparticles. The luminescent hydroxylapatite nanoparticles may find important applications as a biodegradable substrate for biomarking and drug delivery. (C) 2006 American Institute of Physics. [DOI: 10.1063/1.2374687]
\end{abstract}

Nanoparticles, by design at nanometer scale, can be used as drug-delivery vehicles that can target tumor tissues or cells. ${ }^{1}$ Nanoparticles can also be functionalized for qualitative or quantitative detection of tumor cells. ${ }^{1-7}$ In cancer diagnosis and treatment, specific applications often require multifunctional nanoparticles, such as fluorescent signaling, biolinkers, biocompatibility, and drug-carrying capability. The design of the multipurpose nanostructure is the key to the success of this approach. For diagnosis, the nanoparticles must be functionalized with spectrally characteristic fluorescent dyes.

One of the approaches in biomarking is through targeting cancer cells with luminescent nanoparticles, such as quantum dots. $^{8-12}$ Compared to traditional organic fluorophores, quantum dots have superior properties, including higher quantum yield and much sharper emission spectra. Due to these unique properties, extensive research has been carried out on cancer diagnosis by using quantum dots. ${ }^{3-8}$ Anticancer drug-delivery systems require nanoparticles to be porous or have "cavities," i.e., nanospheres and nanotubes, which can be used for the transport of the drug. ${ }^{10-12}$ In our previous research, carbon nanotubes and $\mathrm{Al}_{2} \mathrm{O}_{3}$ nanoparticles were surface functionalized by rare-earth-doped $\mathrm{Y}_{2} \mathrm{O}_{3}$ that exhibit strong visible emissions. ${ }^{13-15}$ However, in the biomedical applications of surface functionalized carbon nanotubes and quantum dots, toxicity has been a major concern as they are not biodegradable. Standard histological tests showed that all the carbon nanotubes made their way into the alveoli of mice, resulting in severe ill effects. ${ }^{16,17}$ Therefore, searching for biodegradable biomarkers and drug-delivery

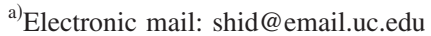

vehicles at the nanoscale is of fundamental importance in biomedical applications of nanotechnology.

In the calcium phosphate system, hydroxylapatite (HA) $\left[\mathrm{Ca}_{10}\left(\mathrm{PO}_{4}\right)_{6}(\mathrm{OH})_{2}\right]$ exhibits superb biological stability and affinity. ${ }^{18,19} \mathrm{HA}$ has been routinely used in orthopedic surgery in both powder and bulk forms. ${ }^{19}$ Due to their biodegradable nature, HA nanoparticles may serve as an ideal candidate for both cancer diagnosis and drug delivery. The critical issues in applying HA as a substrate involve both biomarking and drug-carrying capabilities. It has been found that the HA particle surface is porous that it can be used for drug storage. ${ }^{20-22}$ However, there has been no report on the optical characteristics of HA. In this study, hydroxylapatite (HA) nanoparticles were surface functionalized by depositing optically active rare-earth-doped nanophosphors, i.e., $\mathrm{Y}_{2} \mathrm{O}_{3}: \mathrm{Eu}^{3+}$ nanoparticles, leading to a strong visible luminescence. It should be noted that the $\mathrm{Y}_{2} \mathrm{O}_{3}$ ceramic has been used as a substrate in orthopedic implants as a bio inner material. ${ }^{23}$ Further, the Eu doping level is considered extremely low that it may have negligible toxic effects. We report the experimental results of transmission electron microscopy (TEM) on the surface structures of the HA nanoparticles. The optical behaviors of the functionalized HA nanoparticles are also presented.

$\mathrm{Eu}\left(\mathrm{NO}_{3}\right)_{3} \cdot 6 \mathrm{H}_{2} \mathrm{O}$ and $\mathrm{Y}(\mathrm{COOH})_{3} \cdot \mathrm{H}_{2} \mathrm{O}$ were used as starting reactants, both of which were soluble in water. A total weight of $0.035 \mathrm{~g} \mathrm{Eu}\left(\mathrm{NO}_{3}\right)_{3} \cdot 6 \mathrm{H}_{2} \mathrm{O}$ and $0.5 \mathrm{~g}$ $\mathrm{Y}(\mathrm{COOH})_{3} \cdot \mathrm{H}_{2} \mathrm{O}$ were dissolved in $40 \mathrm{ml}$ de-ionized water at room temperature. After the dispersion process was complete, $0.2 \mathrm{~g}$ HA nanoparticles were added into the solution as prepared. The condensation of $\mathrm{Ca}_{10}\left(\mathrm{PO}_{4}\right)_{6}(\mathrm{OH})_{2}$ took place immediately, and a layer of white precipitation was seen at the bottom of the beaker. After stabilization for $20 \mathrm{~min}$ with 

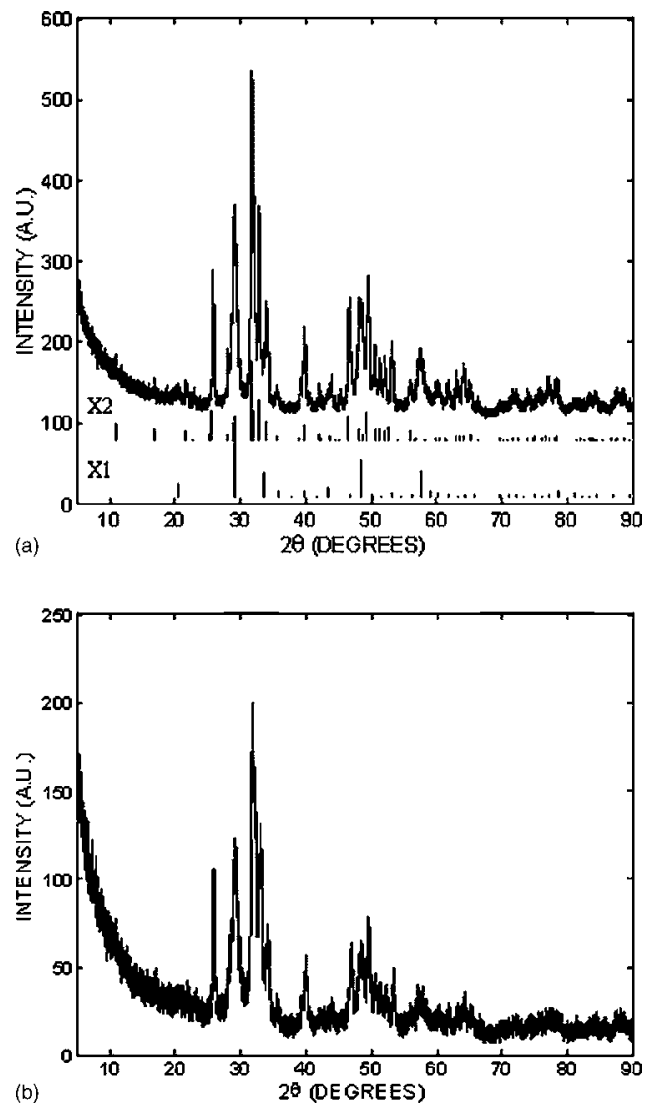

FIG. 1. X-ray diffraction pattern of $\mathrm{Y}_{2} \mathrm{O}_{3}: \mathrm{Eu}^{3+}$ coated $\mathrm{HA}$ particles. Samples are annealed at (a) $850{ }^{\circ} \mathrm{C}$ and (b) $650{ }^{\circ} \mathrm{C}$. Principal diffraction peaks of the $\mathrm{Y}_{2} \mathrm{O}_{3}(\mathrm{X} 1)$ and $\mathrm{Ca}_{10}\left(\mathrm{PO}_{4}\right)_{6}(\mathrm{OH})_{2}(\mathrm{X} 2)$ are shown (Refs. 24 and 25).

intensive magnetic bar stirring, the liquid phase in the system was removed by vaporization at $50{ }^{\circ} \mathrm{C}$. In this process, HA nanoparticles were coated with $\mathrm{Eu}^{3+}$ and $\mathrm{Y}^{3+}$ balanced with $\mathrm{NO}_{3}^{-}, \mathrm{COOH}^{-}$. The as-prepared powders were placed in two quartz containers and annealed in a furnace at 650 and $850^{\circ} \mathrm{C}$ for $12 \mathrm{~h}$, respectively. After annealing, the cooling rate was controlled at a rate of $50{ }^{\circ} \mathrm{C} / \mathrm{h}$ till room temperature was reached. For dehydration, both samples were held at $120{ }^{\circ} \mathrm{C}$ for $1 \mathrm{~h}$. At the maximum temperature, $\mathrm{NO}_{3}^{-}, \mathrm{COOH}^{-}$ were decomposed as $\mathrm{NO}_{x}, \mathrm{CO}_{2}$, and $\mathrm{H}_{2} \mathrm{O}$. The $\mathrm{Y}_{2} \mathrm{O}_{3}: \mathrm{Eu}^{3+}$ coated $\mathrm{HA}\left[\mathrm{Ca}_{10}\left(\mathrm{PO}_{4}\right)_{6}(\mathrm{OH})_{2}\right]$ nanoparticles were characterized by x-ray diffraction (XRD) with $\mathrm{Cu} K \alpha$ radiation ( $\lambda$ $=1.54056 \AA$ ) and JEOL 2010F analytic TEM.

Figure 1(a) shows the XRD patterns of as-prepared samples annealed at $850{ }^{\circ} \mathrm{C}$ with principal diffraction peaks indexed by $\mathrm{Y}_{2} \mathrm{O}_{3}$ (Ref. 24) and $\mathrm{Ca}_{10}\left(\mathrm{PO}_{4}\right)_{6}(\mathrm{OH})_{2}$ (Ref. 25). As shown in Fig. 1(a), the diffraction pattern shows characteristic lines of the HA cubic phase combined with the $\mathrm{Y}_{2} \mathrm{O}_{3}$ cubic phase. As compared to the XRD patterns of the samples annealed at $650{ }^{\circ} \mathrm{C}$ [Fig. 1(b)], the strong diffraction peaks in Fig. 1(a) suggest that the degree of crystallization for both phases, $\mathrm{Y}_{2} \mathrm{O}_{3}$ and $\mathrm{HA}$, is enhanced significantly upon thermal annealing at higher temperatures. The TEM samples were prepared by dispersing nanoparticles directly on holy-carbon films supported with $\mathrm{Cu}$ grids. Figure 2(a) shows a bright-field TEM image of HA nanoparticles annealed at $850{ }^{\circ} \mathrm{C}$. As can be seen in this figure, the HA nanoparticles agglomerate to form large size clusters, and the selected area diffraction patterns from HA nanoparticle clusters [inset in Fig. 2(a)] can be indexed by structural data of

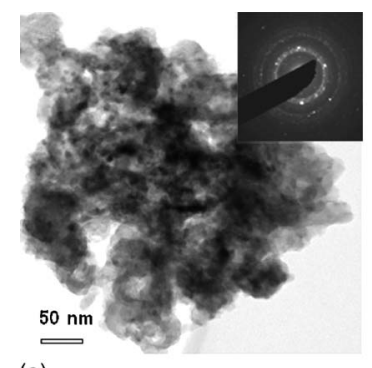

(a)

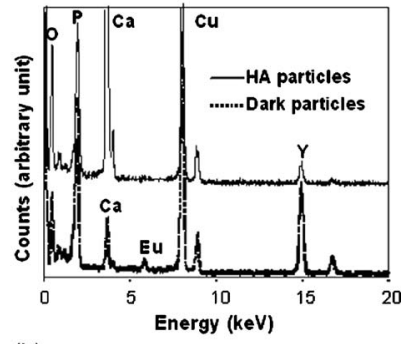

(b)
FIG. 2. Bright-field TEM image showing the typical morphology of $\mathrm{Y}_{2} \mathrm{O}_{3}: \mathrm{Eu}^{3+}$ coated $\mathrm{HA}$ particles heated at $850{ }^{\circ} \mathrm{C}$, and the inset is the selected area electron diffraction pattern from the HA substrate. (b) EDS spectra acquired from the $\mathrm{HA}$ nanoparticle substrate and Eu- $\mathrm{Y}_{2} \mathrm{O}_{3}$ nanoparticles.

the HA cubic phase. Small nanoparticles showing dark contrast were observed to be randomly distributed on the substrate of HA nanoparticle clusters. Energy dispersive spectroscopy measurements were performed by focusing the nanosize electron probe on the HA substrate and dark particles [Fig. 2(b)]. Strong signals of Eu and Y were observed in the energy dispersive spectroscopy (EDS) spectrum acquired from the dark particles, while no Eu signal and only weak peaks of $\mathrm{Y}$ were observed in the spectrum acquired from the HA nanoparticles. These results clearly indicated that these are essentially Eu-doped $\mathrm{Y}_{2} \mathrm{O}_{3}$ nanoparticles coated on the surface of HA nanoparticles. Significant $\mathrm{Ca}$ and $\mathrm{P}$ peaks observed in the spectrum from the dark particles can be attributed to the contribution from the hydroxylapatite substrate. A high resolution TEM image (Fig. 3) shows the nanocrystalline feature of HA particles with random orientations, consistent with the polycrystalline ring patterns in the selected area electron diffraction pattern [inset in Fig. 2(a)]. The lattice image (inset in Fig. 3) of a nanoparticle absorbed on the surface of HA nanoparticle clusters can be indexed as a cubic $\mathrm{Y}_{2} \mathrm{O}_{3}$ phase with [011] orientation, consistent with the EDS measurements. These results suggest that small nanoparticles of Eu-doped $\mathrm{Y}_{2} \mathrm{O}_{3}$ are either randomly embedded within or attached on the surface of the HA substrate.

Figure 4 shows the emission spectra of the $\mathrm{Y}_{2} \mathrm{O}_{3}: \mathrm{Eu}^{3+}$ coated HA particles. Apulsed laser at $355 \mathrm{~nm}$ was used to pump $\mathrm{Eu}^{3+}$ into the excited states above the metastable luminescent state ${ }^{5} D_{0}$. Strong fluorescences due to $\mathrm{Eu}^{3+}$ transi-

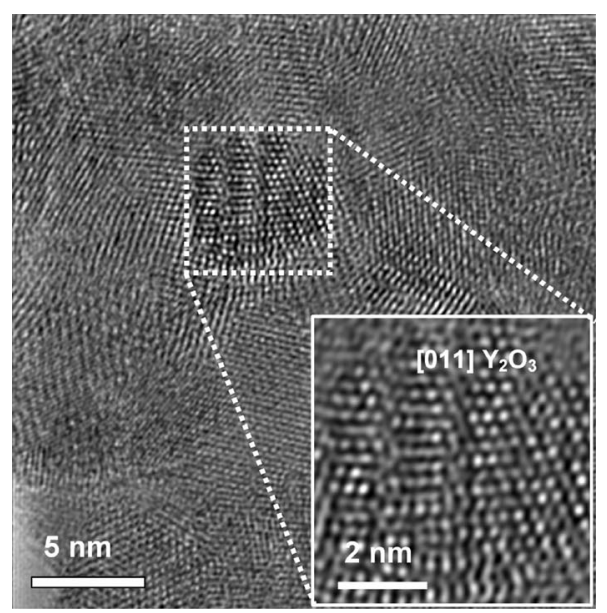

FIG. 3. High resolution TEM image showing the crystalline feature of HA nanoparticles heated at $850^{\circ} \mathrm{C}$. The lattice image (inset in Fig. 3) of a nanoparticle showing dark contrast can be indexed by the structural data of the cubic $\mathrm{Y}_{2} \mathrm{O}_{3}$ phase. 


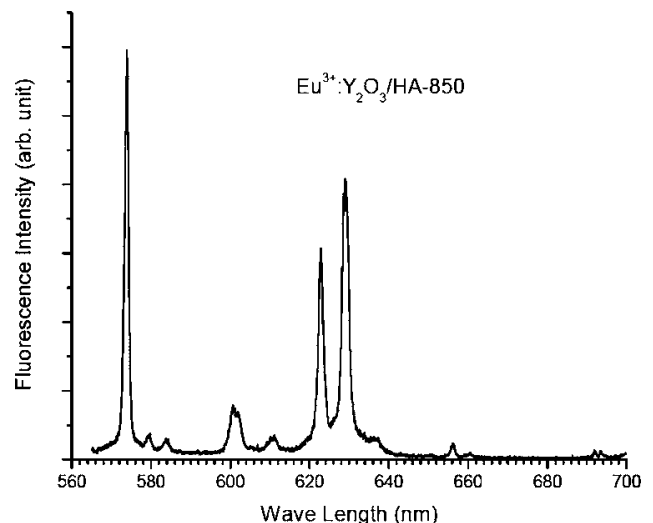

FIG. 4. Luminescence spectra of $\mathrm{Y}_{2} \mathrm{O}_{3}: \mathrm{Eu}^{3+}$ coated $\mathrm{HA}$ nanoparticles heated at $850^{\circ} \mathrm{C}$.

tions of ${ }^{5} D_{0} \rightarrow{ }^{7} F_{0},{ }^{7} F_{1}$, and ${ }^{7} F_{2}$ in the range of $570-640 \mathrm{~nm}$ were observed. The observed $\mathrm{Eu}^{3+}$ luminescence appears greener than the emission from most other $\mathrm{Eu}^{3+}$ phosphors. As shown in Fig. 4, this effect is due to the enhancement of the ${ }^{5} D_{0} \rightarrow{ }^{7} F_{0}$ line centered at $574 \mathrm{~nm}$. A strong ${ }^{5} D_{0} \rightarrow{ }^{7} F_{0}$ line is, however, not typically observed from $\mathrm{Eu}^{3+}$-doped into crystal phases of $\mathrm{Y}_{2} \mathrm{O}_{3}$. At a normal crystalline lattice, the fluorescence line of the ${ }^{5} D_{0} \rightarrow{ }^{7} F_{0}$ transition is always much weaker than that of the hypersensitive ${ }^{5} D_{0} \rightarrow{ }^{7} F_{2}$ transition. ${ }^{26}$ This is consistent with the luminescence spectra we reported previously for Eu-doped $\mathrm{Y}_{2} \mathrm{O}_{3}$ coated on carbon nanotubes ${ }^{14}$ and on the surface of nanocrystals of alumina $\left(\mathrm{Al}_{2} \mathrm{O}_{3}\right),{ }^{15}$ in which the emission intensity of the ${ }^{5} D_{0} \rightarrow{ }^{7} F_{0}$ transition is always weaker than that of ${ }^{5} D_{0} \rightarrow{ }^{7} F_{1,2}$ transitions.

In case the local environment of $\mathrm{Eu}^{3+}$ is perturbed either by an impurity ion such as $\mathrm{O}^{2-}$ or by a structural distortion, the cross section of the ${ }^{5} D_{0} \rightarrow{ }^{7} F_{0}$ transition may be significantly enhanced. ${ }^{27}$ Therefore, the enhanced ${ }^{5} D_{0} \rightarrow{ }^{7} F_{0}$ transition suggests changes of the local environment of $\mathrm{Eu}^{3}$. Such changes could either be by structural distortion of $\mathrm{Y}_{2} \mathrm{O}_{3}$ as deposited on the surface of the nanoscale HA particles or by diffusion of ions across the interphase of the coated $\mathrm{Eu}^{3+}-\mathrm{Y}_{2} \mathrm{O}_{3}$ and the HA nanoparticles. Annealing of nanoparticles coated with a layer of material with a different composition could facilitate atom diffusion and conversion of the coated material into a phase with composition and structure different from those of the original core and shell nanoparticles. ${ }^{13}$ Further investigation on the optical mechanisms is currently underway.

Nanoparticles such as HA particles employed in this study generally have high vapor pressures at elevated temperatures. Their surface structures can be easily damaged via chemical decomposition and etching in the surrounding atmosphere. Furthermore, due to self-balanced vapor pressure in the system, the reactants must decompose and precipitate on the surface of relatively large HA particles during heating. This is an important step to ensure that the rare-earth-doped $\mathrm{Y}_{2} \mathrm{O}_{3}$ particles will not aggregate together but uniformly deposit on the HA particle surfaces. Thus, during the annealing, control of decomposition of reactants, precipitation, and dispersion of Eu-doped $\mathrm{Y}_{2} \mathrm{O}_{3}$ particles are the critical processes. Since the solubility of $\mathrm{Ca}_{10}\left(\mathrm{PO}_{4}\right)_{6}(\mathrm{OH})_{2}$ (calcium hydroxylapatite) in water is low, water can be used as an ideal dis- persion phase for uniformly mixing reactants with the HA nanoparticles on the molecular level.

In summary, $\mathrm{Eu}^{3+}$-doped $\mathrm{Y}_{2} \mathrm{O}_{3}$ nanoparticles have been deposited onto the surface of HA nanoparticles for functionalizing biodegradable substrates for biomarker and drug delivery. The microstructure of rare-earth nanophosphors-HA composites and their optical properties can be controlled by varying the annealing temperature. The $\mathrm{Eu}^{3+}$-doped $\mathrm{Y}_{2} \mathrm{O}_{3}$ on HA exhibits luminescent emission in the visible light range, and the phosphors were associated with doped HA nanoparticles via $\mathrm{Y}_{2} \mathrm{O}_{3}$ as the medium.

The work at Argonne National Laboratory was performed under the auspices of the Office of Basic Energy Science, Division of Chemical Sciences, U.S. Department of Energy under Contract No. W-31-109-ENG-38. The authors of the University of Michigan acknowledge the financial support from the NSF NIRT grant (EAR-0403732). One of the authors (W.W.) is grateful to the financial support from the Chemistry Division, Argonne National Laboratory.

${ }^{1}$ M. Ferrari, Nat. Rev. Cancer 5, 161 (2005).

${ }^{2}$ M. Zhang, M. Yudasaka, and S. Iijima, J. Phys. Chem. B 109, 6037 (2005).

${ }^{3}$ F. Yuan, Semin. Radiat. Oncol. 8, 164 (1998).

${ }^{4}$ S. M. Moghimi, A. C. Hunter, and J. C. Murray, Pharmacol. Rev. 53, 283 (2001).

${ }^{5}$ S. Park, T. A. Taton, and C. A. Mirkin, Science 295, 1503 (2002).

${ }^{6}$ A. C. Gavin, M. Bösche, R. Krause, P. Grandi, M. Marzioch, A. Bauer, J. Schultz, J. M. Rick, A. M. Michon, C. M. Cruciat, M. Remor, C. Höfert, M. Schelder, M. Brajenovic, H. Ruffner, A. Merino, K. Klein, M. Hudak, D. Dickson, T. Rudi, V. Gnau, A. Bauch, S. Bastuck, B. Huhse, C. Leutwein, M. A. Heurtier, R. R. Copley, A. Eldmann, E. Querfurth, V. Rybin, G. Drewes, M. Raida, T. Bouwmeester, P. Bork, B. Seraphin, B. Kuster, G. Neubauer, and G. S. Furga, Nature (London) 415, 141 (2002).

${ }^{7}$ D. R. Walt, Science 308, 217 (2005).

${ }^{8}$ X. Gao, Y. Cui, R. M. Levenson, L. W. K. Chung, and S. Nie, Nat. Biotechnol. 22, 969 (2004).

${ }^{9}$ B. Dubertret, P. Skourides, D. J. Norris, V. Noireaux, A. H. Brivanlou, and A. Libchaber, Science 298, 1759 (2002).

${ }^{10}$ D. R. Larson, W. R. Zipfel, R. M. Williams, S. W. Clark, M. P. Bruchez, F. W. Wise, and W. W. Webb, Science 300, 1434 (2003).

${ }^{11}$ A. M. Derfus, W. C. W. Chan, and S. N. Bhatia, Nano Lett. 4, 11 (2004).

${ }^{12}$ E. B. Voura, J. K. Jaiswal, H. Mattoussi, and S. M. Simon, Nat. Med. 10, 993 (2004)

${ }^{13}$ X. Y. Chen, L. Yang, R. E. Cook, S. Skanthakumar, D. Shi, and G. K. Liu, Nanotechnology 14, 670 (2003).

${ }^{14}$ D. Shi, J. Lian, W. Wang, G. K. Liu, Z. Y. Dong, L. M. Wang, and R. C. Ewing, Adv. Mater. (Weinheim, Ger.) 18, 189 (2006).

${ }^{15}$ J. Lian, L. Yang, X. Y. Chen, G. Liu, L. Wang, R. C. Ewing, and D. Shi, Nanotechnology 17, 1351 (2006).

${ }^{16}$ C. W. Lam, J. T. James, R. McCluskey, and R. L. Hnter, Toxicol. Sci. 77, 126 (2004).

${ }^{17}$ A. Pietropaoli, M. Frampton, R. Hyde, P. Morrow, G. Oberdörster, C. Cox, D. Speers, L. Frasier, D. Chalupa, L. S. Huang, and M. Utell, Inhalation Toxicol. 16, 59 (2004).

${ }^{18}$ W. F. Hench, J. Am. Ceram. Soc. 74, 1487 (1991).

${ }^{19} \mathrm{~K}$. de Groot, in Bioceramics of Calcium Phosphate, edited by K. de Groot, (CRC, Boca Raton, FL, 1983), pp. 100-114.

${ }^{20}$ G. Jiang and D. Shi, J. Biomed. Mater. Res. 43, 77 (1998).

${ }^{21}$ M. Jarcho, Clin. Orthop. Relat. Res. I57, 2592 (1981).

${ }^{22}$ G. Jiang and D. Shi, J. Biomed. Mater. Res. 48, 117 (1999).

${ }^{23}$ M. Hamadouche and L. Sedel, J. Bone Joint Surg. Br., 82-B, 1095 (2000).

${ }^{24}$ JCPDF-International Center for Diffraction Data Card No. 000251200.

${ }^{25}$ JCPDF-International Center for Diffraction Data Card No. 010731731.

${ }^{26}$ Richardson, J. D. Saxe, S. A. Davis, and T. R. Faulkner, Mol. Phys. 42, 1401 (1981).

${ }^{27}$ X. Y. Chen and G. K. Liu, J. Solid State Chem. 178, 419 (2005). 